\title{
Do quadro aos "quadros": o uso de filmes como recurso didático no ensino de administração.
}

\section{From blackboard to frames: the use of films as didactic resource in business teaching}

\author{
J. Ricardo C. de Mendonça ${ }^{1}$
}

Flávia Peixoto Guimarães ${ }^{2}$

\section{Resumo}

Este artigo tem como objetivo apresentar e discutir duas experiências, na graduação e na pós-graduação (Mestrado), nas quais filmes são usados - respectivamente, como estudo de caso e sátira - no ensino de comportamento organizacional e metodologia de pesquisa. Argumenta-se que os filmes são uma poderosa ferramenta não apenas para ilustrar tópicos e conceitos relacionados à administração, mas também para demonstrar aplicações de teorias da área de Comportamento Organizacional, sem contar que podem ser usados para propiciar a discussão sobre abordagens, procedimentos e técnicas de pesquisa. Dessa forma, constituem uma fonte de material pedagógico mais estimulante e motivadora que métodos convencionais de ensino. Esse potencial dos filmes na prática de ensino é demonstrado por meio de dois exemplos baseados, respectivamente, no episódio "Origem Distante" do seriado de ficção científica para TV Jornada nas Estrelas Voyager (Star Trek Voyager) e do longa-metragem Tormenta (White Squall). Defende-se que, com o uso de filmes em sala de aula, os alunos aprendem por meio do processo de aprendizagem social e vivenciam experiências de forma vicária.

Palavras-chave: filmes; recursos didáticos; ensino de administração; aprendizagem social.

\begin{abstract}
The objective of this paper is to present and to discuss two teaching experiences, one in under graduation and another in graduation (Master), in which films are used, respectively, as case study and satire to teach organizational behavior and research methodology. It is argued that the films are a powerful tool to illustrate topics and concepts related to business, as well as to demonstrate applications of theories of organizational behavior area. Besides, films can be used to propitiate the discussion on approaches, procedures and research techniques. In that way, films constitute a more stimulating and motivating pedagogical material source than conventional teaching methods. The potential of films in teaching practice is demonstrated through two examples based, respectively, in the episode Distant Origin, from TV science fiction series Star Trek voyager and of the film White squall. One defends that, with the use of films in classroom, the students learn through social learning, living experiences in a vicarious way.
\end{abstract}

Key words: films; didactic resources; business teaching; social learning.

\footnotetext{
${ }^{1}$ Doutor em Administração pelo PPGA/EA/UFRGS. Professor Adjunto I do Departamento de Ciências Administrativas e PROPAD/UFPE. Endereço: Rua Salvador de Sá, 520 - Ed. Netuno, apto. 403 - Rosarinho. - Recife/Pernambuco - Brasil - CEP: 52041-300 - E-mail: jrcm@ufpe.br

${ }^{2}$ Especialista em Gestão de Serviços. Mestranda em Administração PROPAD/UFPE.Professora na Faculdade Integrada de Pernambuco. Endereço: Rua José Osório, 124 - Madalena - Recife/Pernambuco - Brasil

CEP: 50710-01 - E-mail: flaviapg@yahoo.com
}

Artigo submetido em julho de 2007 e aceito em maio de 2008 


\section{Introdução}

Em um deserto abrasador, dois paleontólogos, ao investigarem uma caverna, descobrem os restos de uma criatura que pode ser o "elo perdido", a prova que faltava para a teoria da origem distante de sua espécie. Extasiados, os cientistas cuidadosamente removem ossos e fragmentos de roupa do que consideram a descoberta mais importante da história da sociedade. Em outro lugar, um grupo de alunos adolescentes alinhados no convés de um "navio escola" prestes a zarpar para uma viagem de um ano, escuta a primeira preleção do capitão, que explica a estrutura de comando, as normas, os valores e as funções dos membros da tripulação. Essas situações poderiam retratar fatos relativamente corriqueiros se não fossem, respectivamente, descrições de cenas de um episódio do seriado de ficção científica Jornada nas Estrelas - Voyager e do filme Tormenta.

Os filmes, conforme Champoux (1999), podem ter muitas funções no ensino, entre elas: filmes como casos, filmes como exercícios experienciais, filmes como metáforas, filmes como sátiras, filmes como simbolismo, filmes como significados, filmes como experiência e filmes como tempo. Conforme Champoux (1999), os filmes podem ter muitas funções no ensino, podendo ser tomados como exemplos de casos, como exercícios experienciais, como metáforas, como sátiras, como simbolismo, como significados, como experiência e como tempo. Este artigo tem como objetivo apresentar e discutir duas experiências de ensino, na graduação e na pósgraduação, nas quais filmes são usados, respectivamente, como estudo de caso e sátira para o ensino de comportamento organizacional e metodologia de pesquisa. Há mais de 10 anos, um dos autores deste artigo vem utilizando filmes como ferramenta didática para o ensino de comportamento organizacional no curso de graduação em administração e em diversos cursos de especialização. Mais recentemente, foram empregados filmes para o ensino na pós-graduação stricto sensu, mestrado e doutorado, também em administração. Segundo Huczynski e Buchanan (2004), a popularidade dos filmes entre os professores baseia-se nas suas capacidades ilustrativa e motivacional.

O uso de diferentes mídias possibilita a apresentação de diferentes sistemas de símbolos para as pessoas, os quais evocam diferentes processos cognitivos, resultando em diferentes padrões, modelos de aprendizagem (CHAMPOUX, 1999). Defende-se que, com o uso de filmes em sala de aula, os alunos aprendem por meio da aprendizagem social, vivenciando experiências de forma vicária. ${ }^{1}$ De acordo com Wagner e Hollembeck (2002), a aprendizagem social é considerada uma teoria observacional, a qual apresenta a idéia de que as pessoas, em sua maioria, aprendem comportamentos observando o comportamento de outros indivíduos e modelando os comportamentos que percebem serem eficazes. Ainda segundo os autores, o aprendizado pela observação diferencia-se do processo de aprendizagem por reforço direto e explica, de uma melhor forma, como os indivíduos aprendem seqüências comportamentais complexas.

Vale salientar que em uma sala de aula, mesmo enquanto assistem a um filme, os alunos (espectadores) estão desempenhando um papel ativo na experiência de ensino/aprendizagem. Como aponta Champoux (1999), os espectadores não são simplesmente observadores passivos das imagens em uma tela; eles podem ter muitas e diferentes respostas, as quais, freqüentemente, tornam-se uma parte essencial da experiência do filme. Dessa forma, na experiência de ensino, o "olhar" e as respostas dos espectadores (alunos) devem ser consideradas um aspecto fundamental. Entende-se neste estudo o "olhar" com base em Aumont e Marie (2003, p.215), os quais afirmam que "o olhar distingue-se da visão pelo fato de emanar do sujeito que percebe, de maneira ativa e mais ou menos deliberada [...] supõe a adoção de um modelo do sujeito e de seu psiquismo". Como entretenimento, reflexos da realidade ou artefatos culturais, os filmes podem moldar e constituir o entendimento da vida social e organizacional. Eles apresentam um "ponto de vista" que o espectador é convidado a inspecionar em relação a sua própria experiência e valores (HUCZYNSKI; BUCHANAN, 2004), característica reveladora do seu grande potencial para o ensino de administração, especialmente, de comportamento organizacional.

Champoux (1999) argumenta que as cenas de um filme podem proporcionar descrições visuais de teorias e conceitos abstratos para o ensino de comportamento organizacional e de gestão. A grande sensação de realidade e a visualização da aplicação de conceitos em diferentes situações podem beneficiar os alunos (CHAMPOUX, 1999). Argumenta-se, então, que os filmes são uma poderosa ferramenta não apenas para 
ilustrar tópicos e conceitos relacionados à administração, mas também para demonstrar aplicações de teorias da área de comportamento organizacional. Além disso, podem ser usados para propiciar a discussão sobre abordagens, procedimentos e técnicas de pesquisa. Dessa forma, os filmes constituem uma fonte de material pedagógico mais estimulante e motivadora que métodos convencionais de ensino (HUCZYNSKI e BUCHANAN, 2004). Com o uso dessa técnica, acredita-se ser possível ultrapassar o universo de informações tradicionalmente circunscrito ao "quadro negro" e levar os alunos a observarem e experimentarem um novo quadro $^{2}$ muito mais rico em possibilidades.

Com base no exposto anteriormente, o potencial do uso de filmes no ensino de administração e uma ilustração de suas aplicações em sala de aula serão mostrados neste artigo por meio de dois exemplos. O primeiro é baseado no filme longa-metragem Tormenta de Ridley Scott, empregado na graduação em administração, na disciplina comportamento organizacional, como um estudo de caso para análise e discussão de tópicos como percepção, atitudes, comportamento grupal e poder, entre outros. O segundo é baseado no episódio "Origem Distante" (Distant Origin) do seriado Jornada nas Estrelas Voyager, e recorre à sátira para retratar abordagens adotadas por alguns estudiosos em suas pesquisas. Adotado na pós-graduação stricto sensu nos cursos de mestrado e doutorado em administração (na disciplina estudos observacionais), o seriado serviu para discutir o processo de observação no campo e possíveis distorções dos dados, originadas das técnicas de coleta empregadas ou do próprio pesquisador observador.

Como se argumenta neste artigo que os filmes proporcionam oportunidades de aprendizagem social em sala de aula, alguns aspectos relacionados a esse tipo de aprendizagem são apresentados a seguir. Cabe observar que o artigo está dividido em quatro seções. Na primeira, são feitas considerações sobre a aprendizagem. Na segunda são discutidos os filmes como ferramentas didáticas. Na terceira são mostradas duas aplicações dos filmes na pós-graduação em administração, seguindo-se as considerações finais e sugestões para futuros estudos.

\section{Aprendizagem social - observação e imitação de modelos}

A aprendizagem social - também conhecida como aprendizagem por observação - é apresentada por Merriam e Caffarella (1999) como uma das cinco principais teorias gerais de aprendizagem que ajudam a compreender como os indivíduos aprendem na idade adulta. Esse tipo de aprendizagem é caracterizado pelo fato de que indivíduos aprendem por meio da observação do comportamento dos outros (MERRIAM; CAFFARELLA, 1999).

O pesquisador Albert Bandura foi o primeiro a estudar a aprendizagem por observação (MYERS, 2006). Em suas pesquisas, Bandura focou mais os processos cognitivos envolvidos na observação do que propriamente os comportamentos originados da observação (MERRIAM; CAFFARELLA, 1999). O ponto central de sua teoria, conforme Merriam e Caffarella (1999), é a distinção entre o processo de observação e o ato de imitar. Catania (2006) salienta que a diferença mais importante entre a aprendizagem social e a imitação é que nesta o comportamento da pessoa que observa corresponde exatamente ao comportamento observado. Em outras palavras, o fato de um indivíduo reproduzir o mesmo comportamento de outro indivíduo não significa que aquele que imita tenha aprendido algo sobre as contingências, o que evidencia que nem todas as imitações podem trazer vantagens (CATANIA, 2006).

No âmago do processo da aprendizagem social há um esquema dinâmico focado em entender os comportamentos dos "modelos" como meio para guiar os próprios comportamentos do indivíduo em situações ou contextos específicos (NATHAN; KOVOOR-MISRA, 2002). Para Ferreira (2000, p.467), um modelo é definido como "aquilo que serve de referência ou que é dado para ser reproduzido", ou ainda como "pessoa ou coisa que serve de exemplo ou norma". Representações cognitivas ou mentais do comportamento modelado são formadas pelo observador e servem como guia para o seu próprio desempenho (NATHAN; KOVOORMISRA, 2002). Merrian e Caffarella (1999) afirmam que, de acordo com os estudos de Bandura, os indivíduos têm a capacidade de regular o seu próprio comportamento, até certo ponto, por anteverem as conseqüências que daí podem advir. Entretanto, Wood e Bandura (1989) salientam que se os indivíduos adquirissem habilidades e conhecimentos apenas por intermédio da experiência direta, certamente, o desenvolvimento do ser humano seria, além de arriscado, muito vagaroso e tedioso. 
Robbins (2005) se refere à aprendizagem social como a aprendizagem obtida tanto pela observação, como pela experiência direta. Dessa maneira, percebe-se que a aprendizagem se dá de maneira mais eficaz, se obtida de ambas as formas. O cerne da abordagem da aprendizagem social é a influência dos modelos, que são representados pelos pais, professores, colegas, chefes, atores de cinema e TV etc. (ROBBINS, 2005). Salientase que para a discussão desenvolvida neste estudo, a influência exercida por atores de filmes de televisão e de cinema tem especial relevância.

Cabe atentar para os diversos processos envolvidos na influência dos modelos (reais ou fíctícios) na aprendizagem. Segundo Robbins (2005), existem quatro processos que determinam a influência que um modelo exerce sobre um indivíduo. São eles:

- processos de atenção - ocorre quando as características críticas do modelo são reconhecidas e despertam atenção. O indivíduo tende a ser mais influenciado por modelos que julgue mais atraentes, que estejam constantemente disponíveis, que the sejam importantes ou semelhantes à sua auto-imagem;

- processos de retenção - um indivíduo será influenciado por um modelo dependendo do quanto se lembre da ação desse modelo quando o mesmo não mais estiver prontamente disponível;

- processos de reprodução motora - diante de um novo comportamento observado no modelo, o indivíduo deve converter a observação em ação, demonstrando sua capacidade de desempenhar a atividade modelada; e

- processo de reforço - caso haja incentivos positivos ou recompensas, os indivíduos serão motivados a exibir o comportamento do modelo. Aqueles comportamentos mais reforçados receberão maior atenção e serão mais amplamente assimilados, além de mais freqüentemente repetidos.

Myers (2006) afirma que para Bandura, o que determina a decisão de um indivíduo em reproduzir ou não o comportamento do modelo, em parte, é o reforço e a punição que poderão ser recebidos tanto pelo modelo como pela pessoa que copia o seu comportamento. A observação permite que o indivíduo aprenda a antecipar as conseqüências de um dado comportamento em situações semelhantes à que está sendo observada (MYERS, 2006). Dessa forma, acredita-se que ao assistirem a um filme como exercício em sala de aula, os alunos podem detectar modelos cujos comportamentos poderão ser reproduzidos por eles, caso esses comportamentos sejam identificados como vantajosos.

Para Nathan e Kovoor-Misra (2002), a aprendizagem vicária não ocorre apenas pela observação de comportamentos de modelos reais ou filmes de pessoas reais, mas também pela visualização de comportamentos ocultos. Isso significa dizer que a imaginação do indivíduo pode criar cenas com potencial para influenciar seu comportamento, assim, como poderiam fazê-lo os eventos reais (NATHAN; KOVOORMISRA, 2002). Dessa forma, aumenta a lista de possíveis modelos, a qual pode incluir modelos simbólicos encontrados, por exemplo, em livros, gravações, manuais, gráficos, como também direcionamentos verbais ou escritos (NATHAN; KOVOOR-MISRA, 2002). Myers (2006) aponta que, de acordo com os estudos de Bandura, os modelos podem apresentar-se como anti-sociais (negativos), podendo surtir efeitos anti-sociais nos indivíduos, e também se apresentar como pró-sociais (positivos, úteis), podendo desencadear efeitos prósociais. Ao que parece, os modelos podem desenvolver um grande poder de influência em relação àqueles que os observam, à medida que "incentivam" de certa forma, os indivíduos a adotarem certos comportamentos que antes não apresentavam.

No sentido de evidenciar o potencial didático dos filmes, é apresentada, a seguir, uma discussão relativa aos aspectos considerados relevantes sobre os filmes como método de ensino.

\section{Filmes como ferramenta didática}

Champoux (1999) aponta que professores têm acesso a vários tipos de meios para ensinar, os quais incluem as formas mais tradicionais, como leitura e discussão de textos, livros, retroprojetores, assim como as formas visuais que incluem projeção de desenhos, projeção de imagens por slides ou por intermédio do computador. Ainda segundo o autor, deve-se incluir nessa lista a utilização dos filmes como ferramenta de ensino, pois há 
um efeito cumulativo positivo quando o educador utiliza múltiplos meios para apresentar um mesmo conceito. Para Barbosa e Teixeira (2007, p.5) "a linguagem cinematográfica oferece a vantagem de conseguir demonstrar com clareza uma situação ou o transcorrer de uma ação, além de impacto emotivo".

Atualmente, filmes são facilmente conseguidos por intermédio de locação ou compra por um valor pouco expressivo, o que os torna um recurso acessível para utilização em sala de aula, tanto na graduação quanto na pós-graduação. Além disso, conforme Champoux (1999), muitos afirmam terem sido bem-sucedidos ao utilizarem filmes como ferramenta didática, pois estes podem auxiliar no ensino de uma vasta gama de disciplinas, haja vista que as técnicas de filmagem são capazes de criar experiências que vão além do que se pode experimentar no mundo real. Essas técnicas permitem ao espectador perceber, bem como interpretar, todos os aspectos da conversação, inclusive, as pistas nãoverbais (movimento dos olhos, expressão facial, movimento do corpo etc.) relevantes à historiado filme, do ponto de vista do diretor (CHAMPOUX, 1999). Segundo Huczynski e Buchanan (2004), obras de fíç̧ão podem ser avaliadas e interpretadas como nenhuma outra fonte de dados, pois os filmes representam aspectos das considerações do seu criador (diretor) sobre a realidade, as quais os expectadores são convidados a avaliar. Dessa maneira, o diretor pode criar cenas com forte carga emocional, satírica ou de extrema comicidade que só possam ser vistas por intermédio dos filmes (CHAMPOUX, 1999).

A exibição de filmes apresenta algumas vantagens, entre as quais:

- atrai a atenção dos alunos;

- mostra de forma mais realística como se realiza uma tarefa;

- tem forte poder de persuasão;

- induz o indivíduo à ação;

- exerce impacto emocional; e

- propicia a reflexão sobre questões éticas na formação de um profissional (BARBOSA; TEIXEIRA, 2007).

Napolitano (2008, p.11) afirma que

trabalhar com o cinema em sala de aula é ajudar a escola a reencontrar a cultura ao mesmo tempo cotidiana e elevada, pois o cinema é o campo no qual a estética, o lazer, a ideologia e os valores sociais mais amplos são sintetizados numa mesma obra de arte.

Acredita-se que a afirmação de Napolitano (2008) também seja válida para as instituições de ensino superior (IES), tanto na graduação quanto na pós-graduação.

Champoux (1999) e Huczynski e Buchanan (2004) sugerem que os filmes podem ser utilizados pedagogicamente de diversas formas, como apresentado a seguir: 


\section{Quadro 1 \\ Função didática dos filmes}

\begin{tabular}{ll}
\hline Filmes como casos & $\begin{array}{l}\text { Um filme com um sólido enredo e uma estória coerente pode funcionar como um } \\
\text { estudo de caso. As cenas de um filme bem dirigido e interpretado apresentam um } \\
\text { material de forma mais dramática e atrativa do que um caso impresso. }\end{array}$ \\
\hline $\begin{array}{l}\text { Filmes como exercícios } \\
\text { experienciais }\end{array}$ & $\begin{array}{l}\text { Os estudantes podem analisar as cenas de um filme como situações-problema, } \\
\text { experimentando situações de tomada de decisão individual ou em grupo. }\end{array}$ \\
\hline Filmes como metáforas & $\begin{array}{l}\text { Os filmes possibilitam criar imagens metafóricas de teorias abstratas e de conceitos, } \\
\text { pois os cineastas, freqüentemente, tentam apresentar as imagens como metáforas de } \\
\text { idéias-chave que pretendem enfatizar. }\end{array}$ \\
\hline Filmes como sátiras & $\begin{array}{l}\text { A sátira é uma efetiva forma de arte para se mentalizar conceitos. Quando bem } \\
\text { realizada, pode deixar uma imagem inesquecível de um determinado conceito que } \\
\text { se queira enfatizar. }\end{array}$ \\
\hline $\begin{array}{l}\text { Filmes como } \\
\text { comunicação simbólica }\end{array}$ & $\begin{array}{l}\text { Determinadas cenas de filmes podem oferecer uma forma simbólica de expor } \\
\text { teorias e conceitos. }\end{array}$ \\
\hline $\begin{array}{l}\text { Filmes como } \\
\text { significados }\end{array}$ & $\begin{array}{l}\text { Um filme é uma excelente mídia para dar significado e substância a teorias e } \\
\text { conceitos, pois os efeitos visuais e auditivos do filme podem transmitir mensagens } \\
\text { melhor do que o discurso escrito ou falado. }\end{array}$ \\
\hline $\begin{array}{l}\text { Filmes como } \\
\text { experiências vicárias }\end{array}$ & $\begin{array}{l}\text { As técnicas cinematográficas (foco, edição, ângulos de câmera, som etc.) permitem } \\
\text { ao diretor criar uma experiência que, freqüentemente, vai além do que pode ser } \\
\text { experimentado na realidade. É possível valer-se dessa característica dos filmes para } \\
\text { proporcionar aos alunos forte experiência que possibilite o aprendizado vicário. }\end{array}$ \\
\hline $\begin{array}{l}\text { Filmes como ilustração } \\
\text { de eventos históricos }\end{array}$ & $\begin{array}{l}\text { Os filmes ambientados em diferentes momentos históricos podem ajudar a revelar } \\
\text { aspectos do comportamento organizacional e da gestão em épocas diversas. }\end{array}$ \\
\hline
\end{tabular}

Fonte: Champoux (1999) e Huczynski e Buchanan (2004).

Especialmente quanto ao ensino de graduação em administração, argumenta-se que o uso de filmes como estudo de caso oferece um grau de riqueza maior do que o proporcionado pelos tradicionais casos impressos. Isso se torna ainda mais pertinente quando se discuti a utilização de filmes na disciplina comportamento organizacional, pois, acredita-se que essa mídia apresenta um amplo leque de possibilidades de observação e análise. Observa-se que na pós-graduação, quando a experiência profissional e o conhecimento teórico estão, em geral, mais consolidados, os filmes podem ser adotados com outras funções. No exemplo apresentado neste texto, salienta-se o uso satírico dos filmes como forma de levar os alunos a pensarem ou repensarem determinados conceitos, por vezes, tomados como certos.

Dessa forma, argumenta-se que, ao se relacionar a utilização de filmes como ferramenta didática com o processo de aprendizagem social, os personagens podem servir de modelos para aqueles que os observam; nesse caso, os alunos de graduação e pós-graduação.

Os filmes na prática - ilustrações da aplicação em sala de aula na graduação e pós-graduação

Antes de mostrar as aplicações de filmes em sala de aula, será discutido o planejamento necessário ao uso dessa ferramenta didática, pois, como afirmam Barbosa e Teixeira (2007, p.5), "a utilização de filmes não é capaz de alcançar todas as suas vantagens quando apresentada sem um planejamento prévio."

Ainda conforme as autoras, planejar o emprego de filmes envolve seis etapas distintas: 
Quadro 2

Etapas do planejamento do uso de filmes em sala de aula

\begin{tabular}{ll}
\hline Etapas & Descrição \\
\hline Programação & Definição do objetivo a ser alcançado com a utilização do filme. \\
\hline Questões norteadoras & $\begin{array}{l}\text { O que queremos fazer: promover, informar ou ensinar? Qual o } \\
\text { tema/questões que vamos retratar? Quem são os destinatários? }\end{array}$ \\
\hline Antes da exibição do filme & $\begin{array}{l}\text { Contextualização do filme a ser apresentado; o que ajuda a criar um } \\
\text { clima psicológico e uma aproximação do tema a ser abordado. O aluno } \\
\text { pode obter algumas informações preliminares sobre o conteúdo do } \\
\text { filme e a relação deste com o que será trabalhado em sala. }\end{array}$ \\
\hline Durante a exibição do filme & $\begin{array}{l}\text { Orientação das atividades. Durante o filme, os alunos podem ser } \\
\text { orientados a tomar notas sobre alguma questão para debate, ou mesmo } \\
\text { tomar notas para a elaboração de relatório. A atenção dos alunos deve } \\
\text { ser direcionada para o objetivo estabelecido na etapa de programação. }\end{array}$ \\
\hline Após a exibição do filme & $\begin{array}{l}\text { Deve ser o momento para verificar o que os alunos entenderam do } \\
\text { filme e qual a relação deste com o conteúdo. Também é o momento } \\
\text { ideal para induzir à reflexão e ao debate. }\end{array}$ \\
\hline Feedback & $\begin{array}{l}\text { Momento em que o ciclo se fecha e que deve remeter às questões } \\
\text { levantadas na primeira etapa. Aqui, o grupo deve elaborar algum tipo } \\
\text { de sistematização a respeito do que foi trabalhado }\end{array}$ \\
\hline
\end{tabular}

Fonte: baseado em Barbosa e Teixeira (2007).

Napolitano (2008), ao discutir o planejamento das atividades e os procedimentos básicos para o uso de filmes em sala de aula, divide a preparação do professor numa fase de planejamento e em outra, de análise do filme. As atividades da fase de planejamento são apresentas no quadro a seguir: 


\section{Quadro 3}

\section{Planejamento das atividades para o uso de filmes em sala de aula}

\begin{tabular}{|c|c|}
\hline FASE 1 - Planejando as Atividades & 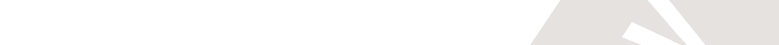 \\
\hline Atividade & Descrição \\
\hline $\begin{array}{l}\text { Pensar no emprego do filme dentro de um } \\
\text { planejamento geral }\end{array}$ & $\begin{array}{l}\text { Insira o filme no planejamento geral de sua disciplina, } \\
\text { articulando-o com os conteúdos e conceitos a serem } \\
\text { trabalhados, relacionando-o ainda com as habilidades } \\
\text { e as competências pretendidas. }\end{array}$ \\
\hline $\begin{array}{l}\text { Selecione um filme, filmes ou seqüências de filmes } \\
\text { a serem apresentadas ao longo da disciplina. }\end{array}$ & $\begin{array}{l}\text { Formule um conjunto de objetivos e metas a serem } \\
\text { atingidos, procurando não apenas articular o(s) } \\
\text { filme(s) à disciplina, mas também realizar uma análise } \\
\text { histórica e fílmica da obra. }\end{array}$ \\
\hline $\begin{array}{l}\text { Procure algumas informações básicas sobre o filme } \\
\text { antes de trabalhá-lo em sala de aula }\end{array}$ & $\begin{array}{l}\text { Toda informação poderá ser útil nas atividades, pois } \\
\text { torna a análise e a mediação do professor mais } \\
\text { interessantes e proveitosas. A sinopse do filme é um } \\
\text { material a ser considerado, assim como informações } \\
\text { sobre o tratamento temático do filme: se possui roteiro } \\
\text { original, se o roteiro é adaptado de fatos reais ou neles } \\
\text { inspirado etc. Diversas outras informações podem ser } \\
\text { relevantes, dependendo dos objetivos do uso do filme: } \\
\text { filmografia do diretor, observações sobre a equipe } \\
\text { técnica, observações sobre os atores e suas } \\
\text { interpretações etc. }\end{array}$ \\
\hline Conheça a cultura cinematográfica da classe & $\begin{array}{l}\text { Para a sondagem e avaliação da cultura audiovisual - } \\
\text { ou especificamente cinematográfica - da classe, o } \\
\text { professor, de maneira informal ou sistematizada, deve } \\
\text { levar em conta algumas informações básicas: qual a } \\
\text { faixa socioeconômica dos alunos, quais os hábitos } \\
\text { culturais e de consumo destes, como funciona o } \\
\text { consumo cinematográfico (salas de cinema, DVDs, } \\
\text { TV), quais os gêneros e filmes preferidos. }\end{array}$ \\
\hline
\end{tabular}

Fonte: baseado em Napolitano (2008).

Ainda com base em Napolitano (2008), são apresentados no Quadro 4 os procedimentos da fase de análise do filme. 
Quadro 4

\section{Procedimentos básicos para o uso de filmes em sala de aula}

FASE 2 - Analisando o(s) Filme(s)

Atividade

Inicie o trabalho em classe

Forneça um roteiro de análise para os alunos

Selecione, se for preciso, textos de apoio

Forme grupos de discussão

Organize uma síntese da discussão grupal, relacionado-a com o conteúdo trabalhado na disciplina

\section{Descrição}

O filme pode ser exibido em sala de aula e ser realizado um debate ou trabalho escrito sobre seu conteúdo. Entretanto, o trabalho de análise não precisa necessariamente iniciar com a exibição do filme em sala. Caso a maioria dos alunos possua aparelhos de vídeo ou DVD e o filme seja de fácil acesso, é mais produtivo que eles assistam ao filme fora do horário de aula. Outro procedimento é selecionar apenas alguns trechos escolhidos do(s) filme(s), trabalhando com cenas e seqüências curtas. Resumindo, há três grandes formas possíveis de exibição/assistência do filme: a) exibição/assistência em sala, dentro do horário de aula; b) assistência em casa, por grupos de alunos previamente formados; e c) exibição, em sala, de cenas ou seqüências selecionadas pelo professor. É fundamental que haja coerência entre a forma de exibição/assistência e os objetivos/amplitude da atividade planejada.

Qualquer que seja o tipo de exibição escolhida, é fundamental a elaboração de um roteiro de análise. Esse roteiro pode ser dividido em duas partes: a) informativa, a título de subsídio para o aluno (uma opção é fazer com que o aluno procure informações sobre o filme ou sobre o tema a ser articulado com o conteúdo do filme); b) interpretativa, provocando o olhar do aluno e delimitando algumas questões básicas a serem percebidas e assimiladas durante a primeira assistência.

Textos de apoio diretamente relacionados ao filme exibido e ao(s) tema(s) teórico(s) abordado(s) podem ser úteis. Esses textos não substituem o roteiro de informação e análise, mas podem funcionar como "textos-geradores" de problemas e questões, enriquecendo a assimilação por parte do aluno.

É necessário que o professor estimule uma análise aprofundada e crie desdobramentos para a atividade. Dessa forma, é importante formar grupos de discussão antes ou após a assistência e a assimilação do filme pelos alunos, de acordo com a forma de exibição/assistência adotada. A primeira análise dos alunos deve ser formalizada em algum nível (trabalho escrito, painel etc.). Compare a leitura que cada grupo fez do filme, sem inibir os alunos, com a sua própria leitura, a qual deve ser mais provocativa que conclusiva. O professor, caso seja preciso, pode exibir trechos do(s) filme(s) que eventualmente causaram mais polêmica, leituras ambíguas ou contrastantes.

Após a primeira assistência, análise sistematizada, discussão dirigida e produção de um trabalho (individual ou grupal), é interessante uma segunda sistematização das análises e de outras questões surgidas, sem que necessariamente esta atividade tenha um caráter conclusivo e definitivo. Valorize as diferenças de opinião e as várias formas de assimilação.

Fonte: baseado em Barbosa e Teixeira (2007). 
O potencial dos filmes na prática de ensino é demonstrado neste tópico por meio de dois exemplos baseados, respectivamente, no episódio "Origem Distante", do seriado de ficção científica para TV Jornada nas Estrelas Voyager, e do longa-metragem Tormenta. A seguir são apresentadas breves descrições dos filmes e de como foram utilizados em sala de aula.

\section{"Origem Distante" na disciplina Estudos Observacionais}

A disciplina Estudos Organizacionais foi oferecida aos alunos de mestrado e doutorado em 2005 e novamente em 2008, com carga horária de 30h/a e com a seguinte ementa: introdução à pesquisa qualitativa, estratégias de estudo de campo e técnicas observacionais, observação e etnografia, dados visuais - as imagens (fotos e filmes) como instrumento e objeto de pesquisa, o relato e a interpretação de dados qualitativos.

Para a discussão dos métodos observacionais, adotou-se o episódio "Origem Distante", do seriado Jornada nas Estrelas Voyager, o qual aborda a prática da pesquisa científica de maneira satírica, ao traçar um paralelo muito próximo com a confrontação histórica entre Galileu e o papa quanto à teoria heliocêntrica de astronomia. A sátira é uma técnica literária ou artística (verbal ou visual) que usa humor e inteligência, principalmente, para ridicularizar o assunto abordado (aspectos do ser humano ou questões sociais, por exemplo). Freqüentemente, expõe com ironia os vícios, as faltas ou os problemas referentes ao assunto abordado, visando provocar ou prevenir mudanças.

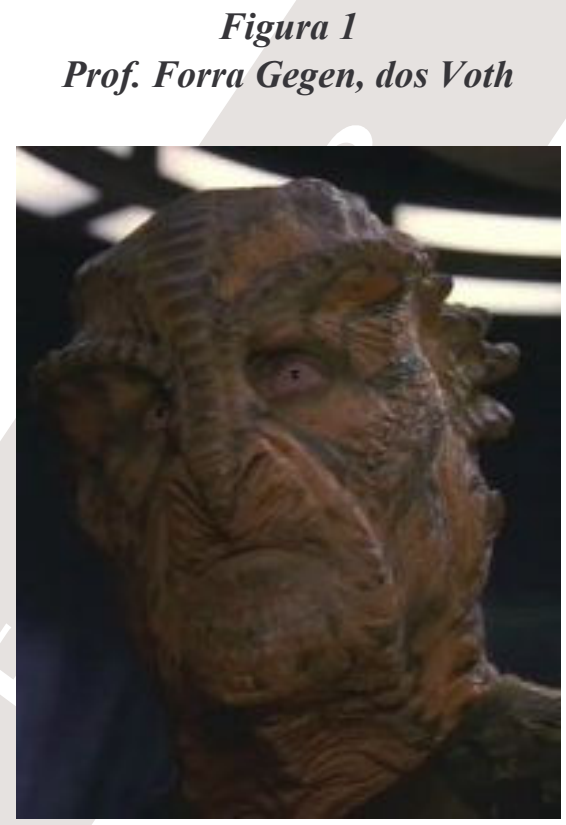

O episódio gira em torno de uma descoberta do Prof. Forra Gegen e de seu assistente Tova Veer durante uma expedição arqueológica num mundo alienígena, quando encontram numa caverna os restos de um oficial da Frota Estelar. O professor acredita que essa descoberta seja a evidência-chave da real origem de sua raça, os Voth, espécie sauriana que ele acredita ter surgido nos confins da galáxia. Essa teoria - a "teoria da origem distante" - contradiz a crença da primeira-ministra Odala e dos poderosos anciões Voth, denominada de "A Doutrina", os quais acreditam serem os primeiros seres inteligentes do quadrante da galáxia. Mesmo sabendo dessa divergência, o Prof. Gegen sai pelo Quadrante Delta da galáxia no encalço da nave Voyager, da qual o oficial encontrado era tripulante, até finalmente encontrá-la.

Graças à sofisticada tecnologia dos Voth, o professsor e seu assistente conseguiram ser tele-transportados, invisíveis, para o interior da Voyager, a fim de iniciarem suas observações não-obstrusivas da estranha espécie. Entretanto, os sensores da nave detectaram Gegen e Veer, e a tripulação conseguiu torná-los visíveis novamente. No decorrer da estória, a Voyager e sua tripulação são capturadas pelo Ministério dos Anciões para 
serem enviados para uma colônia de detenção, pois representam uma ameaça à "doutrina". Para salvar a tripulação, o Prof. Gegen retrata-se de sua teoria, resignando-se com o fato de que a verdadeira herança dos Voth, a origem distante, será mantida em segredo, pelo menos, por enquanto.

Aproximadamente, na terceira aula, já tinham sido lidos e discutidos textos sobre a pesquisa qualitativa e sua prática, sobre diferenças entre a visão positivista e a visão fenomenológica, sobre o projeto da pesquisa qualitativa e sobre aspectos gerais das técnicas observacionais e da etnografia. Foi então solicitado aos alunos que assistissem, em sala de aula, ao episódio "Origem Distante", anotando em seus diários de campo ${ }^{3}$ aspectos que mais lhes chamassem a atenção nesse primeiro olhar informal. Depois de assistirem ao filme, foi pedido que apresentassem suas impressões. A partir de uma primeira assistência (observação), vários aspectos foram apontados: a visão positivista da ciência, a ética em pesquisas que recorrem a técnicas observacionais, o papel do pesquisador no campo e na sociedade, as relações de poder, as questões relativas à hierarquia e ao status, as diferenças culturais, o etnocentrismo, as ideologias, bem como os preconceitos e a resistência à mudança, entre outros. Demonstrando a capacidade que os filmes têm de ilustrar não apenas conceitos teóricos e abordagens, mas também procedimentos e técnicas de pesquisa, destacam-se dois aspectos apontados: "a visão positivistas da ciência" e "o etnocentrismo".

Neste artigo, entende-se que o positivismo segue abordagens científicas tradicionais para o desenvolvimento do conhecimento, para as estratégias de pesquisa, para os métodos e as formas de interpretação dos resultados. A estrutura dos projetos de pesquisa mantém semelhanças com os experimentos conduzidos nos laboratório. O processo de investigação segue vários passos, normalmente partindo de um, ou mais, objetivos na forma de uma hipótese(s) a ser(em) provada(s) ou contestada(s). Segundo, um método para alcançar os objetivos normalmente, uma abordagem quantitativa - é adotado para medir variáveis nos dados. Os dados são coletados - ou geraram por meio de um levantamento (survey), um experimento ou observação - e os resultados são, então, apresentados e uma conclusão é desenvolvida, aceitando ou rejeitando a hipótese testada. É pelo raciocínio dedutivo que são gerados os resultados. Na abordagem positivista de pesquisa, o pesquisador é externo aos eventos, ao fenômeno examinado, e, além disso, os instrumentos de mensuração são objetivos. Os pesquisadores focam fatos e procuram relações de causa e efeito. Os alunos recebem um texto comparando o positivismo com a fenomenologia, o qual é discutido na primeira aula da disciplina.

No episódio "Origem Distante", percebe-se desde o início uma abordagem positivista da ciência. Isso fica evidenciado em vários momentos nas falas dos personagens e nas cenas apresentadas. Durante uma seção de análise forense do esqueleto humano encontrado, o Prof. Gegen lembra ao seu assistente Veer que ele assumiu o "comprometimento de perseguir a verdade científica" (grifo nosso). Na mesma cena, Gegen salienta: "antes disso, tudo que tínhamos era uma teoria. Agora temos provas" (grifo nosso). Nessas falas, parece ficar claro o pressuposto de que existe uma verdade atingível pela ciência e de que, para isso, os cientistas devem formular hipóteses (teorias) e reunir evidências (provas) comprovando ou rejeitando a hipótese. A idéia de coletar "provas" (ou evidências) perpassa todos os diálogos em todo o episódio.

Diante da primeira-ministra Odala, o Prof. Gegen apresenta provas de sua teoria da origem distante e solicita recursos para prosseguir suas pesquisas. Questionando as evidências apresentadas, a primeira-ministra diz em tom sarcástico: "Gostei da colorida estória de como você encontrou estes restos. Aqui, diz que você pagou uma soma substancial para sua localização. [...] Você considerou a possibilidade de ter sido vítima de um trote?" Além de diversos componentes de política, de poder e de dogmas religiosos envolvidos nos comentários de Odala, pode-se perceber a preocupação com a confiabilidade dos dados (ou com evidências reunidas), não somente nessa cena, nem apenas por parte da primeira-ministra, mas também em outros momentos, por Gegen e Veer. No clímax do episódio, o julgamento do professor, a primeira-ministra o acusa de usar a teoria da origem distante para atacar e minar os princípios que guiam a sociedade Voth (doutrina) por quase uma década. Diante da acusação, Gegen responde: "Não é assim! Tenho realizado uma investigação científica. Não tenho problemas com a doutrina" (grifo nosso). A neutralidade assumida por Gegen e seu distanciamento das possíveis implicações sociais e éticas de suas descobertas paleontológicas parecem uma caricatura do cientista positivista. 
A neutralidade não é a única característica da ciência positivista observada no episódio. A preocupação com a validade é explicitamente demonstrada quando a primeira-ministra pergunta a Veer, já coagido a renegar as pesquisas de seu mentor, "qual [...] a validade da análise do professor?" (grifo nosso). A objetividade é destacada quando o Prof. Gegen comenta que deixara seus próprios preconceitos interferirem em seu julgamento dos humanos ao encontrar a Voyager. Também se destaca quando Odala, em tom de vitória, comenta, após Veer desacreditar as análises que realizara com Gegen: "Entusiasmo e paixão nunca estão errados, Veer. Seu único erro foi deixar que [...] distorcessem seu julgamento".

O etnocentrismo - aqui entendido como a convicção quanto à superioridade do grupo étnico do próprio indivíduo - também é observado em várias falas e cenas no filme. Em suas análises iniciais sobre os restos humanos, o Prof. Gegen comenta em tom depreciativo a fisiologia rudimentar do "endotérmico". Quando encontra a Voyager, Gegen usa a tecnologia Voth para ficar fora de fase com o espaço-tempo e afirma: "É improvável que seus sensores primitivos sejam capazes de nos detectar enquanto estivermos defasados ${ }^{4}$.". Ao se transportarem para a nave humana, o primeiro comentário de Veer é - Curioso, eu não esperava o cheiro -, ao qual o Prof. Gegen responde: "Bem, eles são mamíferos, afinal".

O Prof. Gegen e Veer iniciam as suas observações (não-obstrusivas ou não-intrusivas) na Voyager. Nota-se, claramente, o acentuado viés de percepção dos cientistas, oriundo da natureza etnocêntrica de ambos, pois, a cada vez que observam um acontecimento, automaticamente, fazem comparações com a sua própria cultura, considerada superior, o que termina por distorcer a realidade dos fatos. $\mathrm{O}$ próprio Gegen assume que não foi imparcial em suas observações, quando afirma: "Acho que deixei meu preconceito atrapalhar. Eu estava... desconfiado de vocês. Temos relações muito ruins com raças não sáurias. Mamíferos, em particular, são considerados uma... forma de vida inferior, mas devo admitir que nunca conheci um antes". Em diversos outros momentos do filme posturas etnocêntricas são observadas em membros da raça Voth.

Após a primeira assistência - o primeiro olhar informal - foi solicitado aos alunos que, como exercício de casa, revissem o filme, para uma assistência melhor estruturada. Vale ressaltar que nessa segunda etapa do exercício, eles foram instados a adotar um olhar que tivesse como tema o poder. Isso possibilitou observações que focassem fatores indicativos das relações de poder no filme, como: os diálogos (comunicação verbal e nãoverbal), o figurino, o cenário, o comportamento dos personagens, a estrutura hierárquica etc. Os alunos já tinham referências a partir da literatura, além de terem sido orientados pelo professor, sobre como elaborar e usar um diário de campo. Foi verificado que, nessa segunda etapa, a qual contou com um roteiro (ou protocolo de observação) preestabelecido, eles foram capazes de um olhar muito mais apurado, atentando para detalhes antes despercebidos. Dessa maneira, o professor pode chamar-lhes a atenção para os cuidados que o pesquisador deve ter quanto aos diversos aspectos do trabalho de campo e ao uso de diários de campo nas pesquisas em administração.

No sentido de obter um feedback dos alunos quanto ao uso de filmes como ferramenta didática em aulas de pós-graduação - especialmente, em relação ao uso do episódio "Origem Distante" -, foi aplicado um questionário para 15 alunos da disciplina estudos observacionais, ministrada em 2008. Desses alunos, quatro eram doutorandos, um era aluno ouvinte (já mestra) e 10, mestrandos. O questionário era composto por cinco questões abertas e uma questão fechada, referente ao nível do curso (mestrado ou doutorado). As questões abertas e a síntese de suas respostas são apresentadas, de forma o mais literal possível, no Quadro 5. 
Quadro 5

Resultados do questionário de avaliação do uso do filme

\begin{tabular}{l}
\hline Questão \\
\hline \\
1. Qual sua impressão geral sobre a utilização do \\
episódio "Origem distante" como ferramenta de \\
ensino?
\end{tabular}

2. De que forma essa experiência levou você a refletir sobre conceitos e abordagens discutidos em sala de aula?

\section{Transcrição/Síntese das respostas}

Foi boa

Muito boa

Bastante rico

Muito criativa

Muito proveitoso

Interessante

Muito interessante

Bastante interessante

Bastante interessante e rica

Excelente para definir um foco

Vivência prática da observação

Ajudou na prática do assunto estudado

Interessante para observação de comportamentos

Processo direcionado com base em algumas leituras

Deu condições de reforçar as discussões da sala de aula e os textos lidos sobre observação

O vídeo traz uma riqueza de informações que faz com que os conceitos e abordagens discutidas em aula sejam internalizados com mais facilidade

Ampliou o campo de observação em termos de método

Foge da forma tradicional de aula e, de certa forma, instiga a curiosidade

Visualização das cenas que ilustram melhor (imagens)

Trouxe à tona a teoria

A experiência serviu para colocar em prática os conceitos

A observação focada e direta favoreceu a fixação dos debates em sala de aula

Com a anotação do que estava sendo importante para mim 
Pela forma de observação, com um objetivo pré-definido para a experiência

Por poder realizar tarefas práticas sobre conceitos vistos em sala de aula

Por meio do processo de tentar "dominar" os conceitos e opiniões relativas ao tema e a sua teoria de base

A colocação de um caso prático na teoria

Consegui perceber o contexto mais pelas legendas (discurso), porque a visualização não estava boa

O filme é claro, e a primeira leitura já nos reporta às abordagens de poder

O vídeo proporciona descrições visuais relevantes relacionadas à teoria e aos conceitos apresentados

O filme era bastante rico, podendo ser relacionado a vários temas em administração

3. Até que ponto o filme apresentado propiciou descrições visuais de teorias e conceitos abstratos abordados em sala de aula?
O filme tornou possível apreender conceitos, destacando-se o papel da imagem, do som e do ambiente

Os conceitos e descrições de teorias foram fartamente ilustrados no filme

O que mais me chamou a atenção foi perceber que a falta da teoria pode atrapalhar a observação

Foi excelente por mostrar a observação como ferramenta que exige cuidado

Numa aplicação direta de conceitos, foram identificados muitos pontos teóricos relevantes

4. Você acredita que o uso de filmes como fonte de material pedagógico é mais estimulante e motivador do que métodos convencionais? Por quê?

Sim. Os métodos audiovisuais apresentam mais recursos

Sim. Usamos diversos sentidos e temos condições de voltar à cena, dessa forma a aprendizagem vai sendo clara e sedimentada

Sim, pois foge da técnica tradicional, dos métodos rotineiros, da maneira convencional

Sim. Porque gera interesse e estímulo, ao mostrar uma ilustração dos conceitos 
Sim. Porque traz a teoria para reflexão

Sim. O estímulo para o aprendizado se torna mais interessante, quebrando a monotonia na forma prática de observar os conceitos

Sim, por que conseguimos visualizar e dimensionar, de maneira mais prática, os conceitos teóricos debatidos em sala de aula

Sim. Ajuda a prender a atenção do aluno

É atual e, por isso, motivador e mais didático

É estimulante. O continuum para identificar se é mais ou se é menos estimulante vai depender da dinâmica como o exercício é preparado e apresentado

Não diria que é mais motivante. É mais uma entre tantas opções. É preciso mesclar para manter a motivação

Sim., como método auxiliar; principalmente, para representar fielmente o ambiente, a situação e suas intersubjetividades

Sim. Tanto filmes, quanto fotos, figuras e ilustrações (enfim, recursos audiovisuais) são mais facilmente entendidos e lembrados por quem está estudando

5. Como a observação das experiências vivenciadas pelos personagens do filme contribuiu para o seu aprendizado?
Associando experiências anteriores (ou a nossa bagagem de conhecimento) ao conteúdo da disciplina e fazendo as associações

Pelas relações estabelecidas entre os personagens, os diálogos e o contexto, o que nos deu possibilidade de utilização e familiarização com o diário de campo. O diário de campo é um exercício muito útil

Assistir às interações dos personagens foi fundamental para meu aprendizado. Outros aspectos, como ambiência e elementos tangíveis complementares às interações, também foram relevantes

Contribuiu, à medida que observei as ações, falas, ambientes, indumentária, com a teoria do poder; fora a aprendizagem no sentido teoria e prática das técnicas observacionais 
A análise do filme possibilitou que eu visualizasse a teoria (proposta de assunto a ser observado) aplicada e compreendesse de forma vivencial a teoria discutida em sala

Para a reflexão dessas experiências com base nos conceitos abordados

Como cientista me identifiquei com os pares no filme e observei o ambiente político da academia

Pela aplicação dos conceitos e teorias usados em aula

A partir do exercício, do ser permitido "errar" e poder entender outras formas de se alcançar os objetivos do exercício. $\mathrm{O}$ debate posterior sobre o exercício foi fundamental

Através da análise e junção com teorias facilmente lembrado do que os métodos convencionais, ou se tivesse ficado apenas na leitura

De forma positiva. O exercício ou o exemplo vivenciado é mais eficiente do que uma simples leitura ou apenas a exposição do professor

Ajudou bastante com relação à crítica, aos estereótipos e à busca por referenciais teóricos

Particularmente, vivenciar - nem que seja assistindo - as experiências de personagens se torna importante na concepção do comportamento do indivíduo, do grupo e da sociedade em que este se insere, em determinada época. Aprender, vivenciando ou praticando, torna-se mais prazeroso e fácil. Observar faz parte do aprendizado, e com o filme pude voltar a algumas cenas e aspectos para melhor compreendê-los 
Como se pode observar pelas respostas obtidas na primeira questão, a atividade foi bem aceita pelos alunos. Ao que parece, de acordo com as respostas obtidas nas demais questões, eles conseguiram captar a importância da atividade para o aprendizado na disciplina. Na prática, isso corrobora a afirmação de Barbosa e Teixeira (2007), apresentada anteriormente, quanto às vantagens do uso de filmes como ferramenta didática: atrair a atenção dos alunos, mostrar de forma mais realística como se realiza uma tarefa, o poder de persuasão e de convicção, a indução do indivíduo à ação, o impacto emocional e a capacidade de propiciar reflexão sobre questões éticas na formação de um profissional.

De maneira geral, os alunos concordaram que o exercício realizado foi muito proveitoso, pois segundo eles, a atividade possibilitou visualizar "na prática" muitas questões abordadas na teoria discutida em sala de aula. Algumas expressões utilizadas pelos alunos - tais como "riqueza de informações", "facilidade de entender conceitos" e "reflexão das experiências vividas pelos personagens com base nos conceitos abordados" corroboram a capacidade dos filmes de ilustrar conceitos teóricos e abordagens de uma maneira que facilita o aprendizado. Dessa forma, a partir dos depoimentos apresentados no Quadro 4, acredita-se que os objetivos do professor foram alcançados de forma satisfatória.

A seguir, será apresentada a experiência de utilização do filme Tormenta como ferramenta de ensino em cursos de graduação em administração.

\section{"Tormenta" na disciplina Comportamento Organizacional}

A disciplina Comportamento Organizacional faz parte do currículo dos cursos de graduação em administração de uma universidade federal e de uma faculdade privada. Em ambas as instituições, basicamente, engloba a seguinte ementa:

- introdução ao comportamento organizacional;

- fundamentos do comportamento individual (percepção, personalidade, atitudes, satisfação no trabalho e comprometimento, aprendizagem e estresse);

- conceitos básicos de motivação;

- fundamentos do comportamento de grupo;

- grupos e equipes de trabalho;

- liderança nas organizações;

- poder;

- política nas organizações; e

- administração do conflito.

Um dos filmes escolhidos como estudo de caso para análise na disciplina Comportamento Organizacional, entre 1996 e 2007, foi o filme Tormenta, um drama baseado em fatos reais. Lançado nos EUA em 1996, o filme tem 128 minutos de duração e está disponível em VHS e DVD. A escolha desse filme para utilização em sala de aula foi baseada na percepção dos docentes responsáveis pela disciplina, de que essa obra possibilita a observação e discussão de, praticamente, todos os tópicos abordados na disciplina. 


\section{Figura 2}

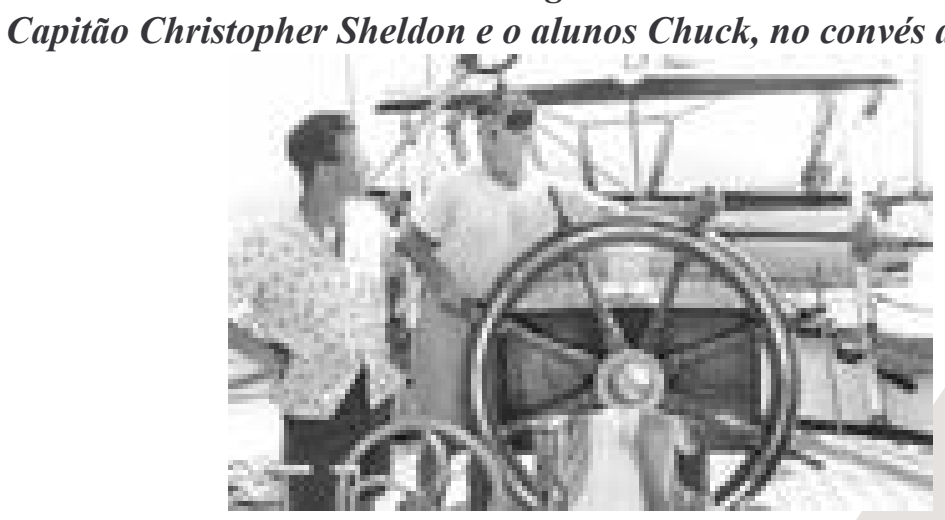

No outono de 1960, 13 jovens admitidos como estudantes no veleiro "Albatroz" - uma escola flutuante altamente seletiva - iniciam uma aventura que mudará suas vidas para sempre. Eles participam de um rigoroso programa de estudos, enquanto passam um ano no mar com a com os tripulantes da embarcação. Durante a viagem, os meninos são conduzidos além da adolescência, enquanto exploram os mistérios do Caribe e do Pacífico Sul. Porém, à medida que o veleiro se aproxima do fim de sua viagem, enfrenta um temporal extremamente violento conhecido como "tormenta". Em poucos minutos, a embarcação naufraga, provocando a morte de quatro estudantes e dois tripulantes; inclusive, da esposa do capitão. Dois sobreviventes são resgatados após dois dias em alto-mar e, posteriormente, forçados a participar do julgamento do capitão do “Albatroz”, Christopher Sheldon, responsabilizado pelo acidente.

No início da disciplina os alunos recebem um roteiro com as instruções detalhadas de como devem realizar a análise do filme indicado no semestre, roteiro esse que deverá ser entregue no dia da segunda avaliação, conforme apresentado no quadro 6.

\section{Quadro 6}

\section{Roteiro para análise do filme}

A análise deve ser realizada com relação ao comportamento dos personagens principais e aos comportamentos considerados relevantes para a história. Assim, em primeiro lugar, o grupo deve definir quais os personagens considerados principais. Basicamente, devem ser abordados os tópicos a seguir:

\begin{tabular}{|c|c|c|}
\hline \multirow{4}{*}{$\begin{array}{l}\text { O indivíduo na } \\
\text { organização }\end{array}$} & Percepção & $\begin{array}{l}\text { descrevam o quadro de referência dos personagens principais (valores, } \\
\text { experiência de vida, traços, socioculturais etc.); } \\
\text { identifiquem as principais distorções perceptivas observadas; e } \\
\text { apontem como essas distorções influenciaram os comportamentos. }\end{array}$ \\
\hline & Atitudes & $\begin{array}{l}\text { identifiquem as principais atitudes em relação a pessoas, ao trabalho e ao } \\
\text { grupo; } \\
\text { apontem e expliquem as possíveis mudanças de atitudes ocorridas; e } \\
\text { descrevam como as atitudes influenciaram comportamentos dos } \\
\text { personagens principais. }\end{array}$ \\
\hline & Personalidade & $\begin{array}{l}\text { identifiquem os principais atributos de personalidade; ou seja, trace um } \\
\text { perfil da personalidade dos protagonistas; e } \\
\text { demonstrem como esses atributos de personalidade influenciaram } \\
\text { comportamentos. }\end{array}$ \\
\hline & Aprendizagem & $\begin{array}{l}\text { identifiquem exemplos de aprendizagem social e de aprendizagem } \\
\text { operante; e } \\
\text { explique como esses processos de aprendizagem influenciaram } \\
\text { comportamentos. }\end{array}$ \\
\hline Motivação & $\begin{array}{l}\text { Teoria da } \\
\text { Expectativa }\end{array}$ & $\begin{array}{l}\text { analisem os processos motivacionais dos personagens principais; } \\
\text { por meio de exemplos específicos, analisem os seguintes fatores: } \\
\text { valência, esforço, expectativa, auto-eficácia, resultados, } \\
\text { instrumentalidade e desempenho. }\end{array}$ \\
\hline
\end{tabular}




\begin{tabular}{|c|c|c|}
\hline \multirow[t]{3}{*}{ Grupos } & $\begin{array}{l}\text { Formação de } \\
\text { grupos }\end{array}$ & apontem as principais razões para a formação dos grupos. \\
\hline & Tipos de grupos & $\begin{array}{l}\text { identifiquem os principais grupos formais e informais; e } \\
\text { expliquem como as razões para a formação do grupo e o tipo de grupo } \\
\text { formado influenciaram o comportamento intragrupal. }\end{array}$ \\
\hline & $\begin{array}{l}\text { Comportamento } \\
\text { grupal }\end{array}$ & $\begin{array}{l}\text { analisem o comportamento dos grupos com relação aos elementos da } \\
\text { estrutura grupal: papéis, normas, coesão, tamanho, composição e status; e } \\
\text { avaliem se os grupos estudados desenvolveram características de equipe. } \\
\text { Justifiquem a sua análise. }\end{array}$ \\
\hline Liderança & \multicolumn{2}{|c|}{$\begin{array}{l}\text { identifiquem as principais lideranças; } \\
\text { definam os tipos de liderança exercidos; e } \\
\text { explique como a liderança influenciou os comportamentos }\end{array}$} \\
\hline Poder & \multicolumn{2}{|c|}{$\begin{array}{l}\text { apontem as bases de poder dos personagens principais; } \\
\text { identifiquem fatores situacionais que conferiram poder a indivíduos ou a grupos; e } \\
\text { analise as estratégias cooperativas de poder. }\end{array}$} \\
\hline Conflito & \multicolumn{2}{|c|}{$\begin{array}{l}\text { estabeleça a natureza e as principais fontes de conflito; } \\
\text { descrevam os estágios dos principais processos de conflito identificados; } \\
\text { descreva como os conflitos foram administrados; e } \\
\text { explique como os conflitos influenciaram os comportamentos. }\end{array}$} \\
\hline
\end{tabular}

De posse desse roteiro, os alunos foram instruídos a formarem grupos de no máximo cinco componentes, para assistirem ao filme e iniciarem o trabalho. Ao longo da disciplina, os grupos puderam recorrer ao professor para esclarecer eventuais dúvidas a respeito das análises. Portanto, o trabalho realizado trata-se de um estudo de caso dirigido, onde o objetivo do docente foi auxiliar o desenvolvimento do senso crítico do aluno em relação aos conceitos discutidos em aula, assim como aguçar a capacidade de observação dos mesmos, possibilitando relacionar a teoria com a prática.

Como exemplo de uma das análises realizada pelos alunos, pode ser citada a cena em que um grupo de alunas holandesas em excursão ao "Albatroz" é recepcionado por um dos tripulantes. Enquanto explica o funcionamento da embarcação, Charles "Chuck" Gieg tem a mesma postura corporal do capitão do veleiro, de quem reproduz, inclusive, as mesmas palavras e entonação quando diz às visitantes que "Esse veleiro não é um brinquedo, senhoras. Respeitem isso e tudo dará certo." Essa observação revela que os alunos da graduação foram capazes de identificar, claramente, um exemplo de aprendizagem social na "prática".

Outro exemplo diz respeito à cena em que o capitão Sheldon pede à tripulação que ao ouvirem uma ordem, repitam-na em voz alta para que ele tenha certeza de que a mensagem fora transmitida e compreendida. Tratase de um exemplo de tentativa de comunicação eficaz.

Em outro momento, o capitão pede para que os alunos comecem a cantar enquanto trabalham em conjunto, argumentando que a música serve para que todos saibam que devem trabalhar em sincronia, no mesmo ritmo. O exemplo demonstra a importância do trabalho em grupo e como este deve ser feito.

Além dessas cenas, muitas outras mostram Sheldon como detentor do poder. Numa delas, muito marcante, um dos estudantes, diverte-se atirando um arpão num golfinho, sendo por isso, como castigo, expulso do navioescola pelo capitão, o que evidencia o domínio da base de poder coercitivo.

Ao final da disciplina - especificamente, no dia da entrega do trabalho escrito-, foi promovido um debate sobre o filme com os grupos, para que avaliassem o nível de compreensão e de aprendizagem dos conceitos e teorias discutidos em aula. Nessa discussão, foi possível esclarecer pontos ainda não assimilados e ressaltar a importância dessa atividade para o desenvolvimento profissional. É argumentado que, se o aluno exercita a habilidade de analisar o comportamento dos personagens principais do filme, terá maiores probabilidades de sucesso ao tentar compreender o comportamento das pessoas nas organizações. 
Vale destacar que o exercício com o uso de filmes, tanto na pós-graduação (mestrado e doutorado) quanto na graduação em administração, não foi desenvolvido nem aplicado de forma aleatória e sem planejamento. Os filmes foram escolhidos de acordo com os temas abordados nas disciplinas, assim como os roteiros para a análise dos mesmos. As discussões foram mediadas pelos professores responsáveis, os quais propiciaram o debate e reflexão, esclareceram dúvidas e aprofundaram teorias e conceitos. Em ambos os casos, foi feita uma síntese das análises (debate em sala, na pós-graduação, e trabalho escrito e debate em grupo, na graduação). Os procedimentos adotados parecem ir ao encontro das orientações de Barbosa e Teixeira (2007) e de Napolitano (2008), apresentadas anteriormente nos quadros 2,3 e 4.

\section{Considerações finais}

Acredita-se que o objetivo deste artigo foi atingido, pois foram apresentadas e discutidas duas experiências de ensino, na pós-graduação e na graduação em administração, nas quais filmes foram usados, respectivamente, como sátira e estudo de caso para o ensino de metodologia de pesquisa e de comportamento organizacional.

Argumenta-se que, ao utilizar filmes como metodologia de ensino, o educador deve ter em mente, de forma clara, o objetivo de utilizar-se de tal metodologia. Deve ter o cuidado de escolher filmes nos quais o comportamento dos modelos melhor represente as teorias apresentadas nas aulas, despertando interesse nos espectadores e propiciando a formação das imagens mentais apropriadas, como uma tentativa de atingir melhores resultados no aprendizado dos alunos.

Como sugestão para futuros estudos e com fins didáticos, é proposto aqui a discussão e o uso de filmes como exercícios experienciais, como metáforas, como comunicação simbólica, como significados e como ilustração de eventos históricos (CHAMPOUX, 1999). Deve ser enfatizada a necessidade de se explorar mais detalhadamente os filmes, em especial, como experiências vicárias, buscando relacionar sua utilização no ensino à teoria da aprendizagem social.

Um aspecto que merece atenção no uso de produções comerciais para o ensino é a dublagem e as legendas. A tradução do texto original, bem como a interpretação dos dubladores, pode modificar o conteúdo e o entendimento da obra. Entretanto, mesmo esse problema pode ser considerado uma oportunidade didática para discutir aspectos ligados à comunicação humana.

Além de explorar longas-metragens e seriados de TV, também cabe trabalhar desenhos animados no ensino de outras disciplinas em administração, tanto na graduação quanto na pós-graduação. Da mesma forma, podem ser utilizados os documentários, um dos gêneros mais utilizados em salas de aula. 


\section{Referências}

AUMONT, Jacques; MARIE, Michel. Dicionário teórico e crítico de cinema. São Paulo: Papirus, 2003.

BARBOSA, Andréa Rodrigues; TEIXEIRA, Luiza Reis. A utilização de filmes no ensino de administração. In: Encontro de Ensino e Pesquisa em Administração e Contabilidade, EnEPQ, 1., 2007, Recife. Anais... Recife, nov. 2007.

CATANIA, Charles A. Aprendizagem: comportamento, linguagem e cognição. Porto Alegre: Artmed, 2006.

CHAMPOUX, Joseph E. Film as a teaching resource. Journal of Management Inquiry, v.8, n.2, p.206-217, June 1999.

FERREIRA, Aurélio Buarque de Holanda. Miniaurélio século XXI: o minidicionário da língua portuguesa. Rio de Janeiro: Nova Fronteira, 2000.

GIOIA, Dennis A.; MANZ, Charles C. Linking cognition and behavior: a script processing interpretation of vicarious learning. Academy of Management Review, v.10, n.3, p.527-539, 1985.

HUCZYNSKI, Andrzej; BUCHANAN, David. Theory from fiction: a narrative process perspective on the pedagogical use of feature film. Journal of Management Education, v.28, n.6, p.707-726, Dec. 2004.

MERRIAM, S.; CAFFARELLA, R. Learning in adulthood: a comprehensive guide. San Francisco: Jossey-Bass, 1999.

MYERS, David G. Psicologia. Rio de Janeiro: LTC, 2006.

NAPOLITANO, Marcos. Como usar o cinema em sala de aula. 4.ed. São Paulo: Contexto, 2008.

NATHAN, Maria L.; KOVOOR-MISRA, Sarah. No pain, yet gain: vicarious organizational learning from crises in an inter-organizational field. The Journal of Applied Behavioral Science, vol.38, n.2, p.245-266, June 2002.

ROBBINS, Stephen P. Comportamento organizacional. São Paulo: Pearson Prentice Hall, 2005.

WAGNER, John A.; HOLLEMBECK, John R. Comportamento organizacional. São Paulo: Saraiva, 2002.

WOOD, Robert; BANDURA, Albert. Social cognitive theory of organizational management. The Academy of Management Review, v.14, n.3, p.361-384, Jul. 1989.

\footnotetext{
${ }^{1}$ A aprendizagem vicária caracteriza-se por ser um tipo de aprendizagem que ocorre por meio de processos vicários ou simbólicos, em lugar da experiência direta (GIOIA; MANZ, 1985).

${ }^{2}$ A imagem fílmica é concebida como enquadrada, limitada por um quadro (moldura). O quadro define o que é imagem e o que está fora da imagem (AUMONT; MARIE, 2003).

${ }^{3} \mathrm{Na}$ disciplina estudos observacionais, é pedido aos alunos que comprem um pequeno caderno, a ser utilizado como diário de campo nas atividades em sala e no trabalho final.

${ }^{4}$ Faz parte da pseudociência de Jornada na Estrelas um aparelho denominado "dispositivo de camuflagem", o qual pode gerar um campo de energia capaz de tornar um determinado objeto - normalmente uma espaçonave, devido ao imenso consumo de energia, praticamente invisível a detecção, visual ou por sensores. A tecnologia de camuflagem Voth é mais avançada não apenas por ser de uso individual, mas também por colocar seus usuários fora de sincronia com as dimensões espaço e tempo.
} 